\title{
Pilot study of DNA methylation in the pathogenesis of chronic rhinosinusitis with nasal polyps*
}

\author{
YongBo Zheng', Yu Zhao', LiYan Yue1, Ping Lin'1, YaFeng Liu'1, JunMing Xian', , Rhinology 53: 345-352, 2015 \\ GuangYao Zhou', DeYun Wang ${ }^{2}$ \\ DOl:10.4193/Rhino14.086 \\ ' Department of Otorhinolaryngology, Head \& Neck Surgery, West China Hospital, Sichuan University. No.37 Guo Xue Xiang, \\ Chengdu, Sichuan, China \\ *Received for publication: \\ ${ }^{2}$ Department of Otolaryngology, Yong Loo Lin School of Medicine, National University of Singapore, Five Lower Kent Ridge \\ February 1, 2014 \\ Accepted: March 22, 2015 \\ Crescent, Singapore
}

\begin{abstract}
Background: DNA methylation has been implicated in the pathogenesis of allergy and atopy. This study aimed to identify whether DNA methylation also plays an important role in the pathogenesis of nasal polyps (NP).
\end{abstract}

Methodology: NP tissues were obtained from 32 patients with chronic rhinosinusitis with bilateral NP. Biopsies of inferior turbinate mucosa (ITM) were taken from 18 patients who underwent rhinoseptoplasty (control group). The methylated genes, which were detected by DNA methylation microarray, were validated by methylation-specific polymerase chain reaction, bisulphite sequencing, real-time polymerase chain reaction and immunohistochemistry.

Results: DNA methylation microarray identified 8,008 CpG islands in 2,848 genes. One hundred and ninety-eight genes were found to have a methylated signal in the promoter region in NP samples compared with ITM samples. The four top genes that changed, COL18A1, EP300, GNAS and SMURF1, were selected for further study. The methylation frequency of COL18A1 was significantly higher in NP samples than in ITM samples.

Conclusions: DNA methylation might play an important role in the pathogenesis of NP. Promoter methylation of COL18A1 was found to be significantly increased in NP tissues, further studies are necessary to confirm the significance of these epigenetic factors in the mechanisms underlying the development or persistence of NP.

Key words: DNA methylation, nasal polyps, gene, microarray, pathogenesis, chronic rhinosinusitis, promoter

\section{Introduction}

Nasal polyp (NP) is a common nose disease that can appear in isolation or accompanying chronic rhinosinusitis (CRS), allergic rhinitis, asthma or atopy. The prevalence of NP ranges from $0.2 \%$ to $4.3 \%$ worldwide with a male-to-female ratio of 2-3:1 $(1,2)$. There are still many unknowns regarding NP's pathogenic mechanisms, although it has been broadly discussed. In recent years, it had been indicated that NP was closely related to allergic diseases ${ }^{(3)}$.

DNA methylation plays an important role in cell metastasis, embryonic development, genetic imprinting, and human tumours. Some previous studies have shown that DNA methylation contributes to the pathogenesis of allergy and atopy. White et al.
(4) found that promoter methylation was a mechanism to control human IFNG expression, and differential regulation of IFNG promoter methylation in T cells might be an important contributory factor in atopy development in childhood. Baron et al. ${ }^{(5)}$ demonstrated that DNA demethylation of FOXP3 constituted the most reliable criterion for development and function of regulatory T cells (Treg); the number and functional activity of Treg cells appears to be crucial in the prevention of autoimmunity and allergy. Epigenetic mechanisms including DNA methylation are currently providing new perspectives in the studies of allergy and atopy.

The evidence that DNA methylation is involved in the pathogenesis of allergy and atopy led us to hypothesize that DNA methylation might also be involved in the pathogenesis of NP. This 
study might provide a new direction to investigate the genetic mechanisms of NP's pathogenesis.

\section{Materials and methods}

Subjects

The present study was approved by the Ethics Committee of West China Hospital, Sichuan University. The diagnosis criterion was based on the European Position Paper on Rhinosinusitis and Nasal Polyps 2012 (EP3OS 2012) (1). NP tissues were obtained from 32 patients with CRS with bilateral NP undergoing endoscopic sinus surgery, 23 males and nine females aged between 18 and 60 years (mean 38.3 years). Of these, seven patients (7/32) had positive skin prick test results to a standard panel of aeroallergens. None of these patients had intolerance to aspirin or immunodeficiency. None had received intranasal glucocorticoid therapy within the last month or antibiotics or oral steroids in the last two months before surgery. Control tissues from normal inferior turbinate mucosa (ITM) were obtained from 18 patients who underwent rhinoplasty, 13 males and five females between the age of 18 and 52 years (mean 28.2 years). The control group was free of any nasal or sinus disease except nasal septum deviation, and endoscopy revealed no signs of mucosal inflammation. Informed consent was obtained from all participants.

Fresh tissue specimens were quickly cleaned with $0.9 \%$ normal saline and sliced into appropriate pieces. Tissues for DNA and RNA extraction were snap-frozen in liquid nitrogen and stored at $-80^{\circ} \mathrm{C}$. Tissues for immunochemical staining were fixed in $4 \%$ formalin, and then embedded into paraffin.

\section{DNA methylation microarray}

DNA methylation microarray, which is a combination of immunoprecipitation of methylated DNA and DNA microarray, was used to detect the methylation status of $\mathrm{CpG}$ islands in all samples ${ }^{(6)}$. Total DNA was extracted from tissues using DNeasy Blood \& Tissue Kit (Qiagen, Valencia, CA, USA). DNA of each sample $(11 \mu \mathrm{g})$ was sonicated in $300 \mu \mathrm{l}$ distilled water. For each sample, the volume of methylated DNA immunoprecipitation (MeDIP) tube and negative control tube (each with $5 \mu \mathrm{g}$ genomic DNA) were adjusted to $500 \mu \mathrm{l}$, and the volume of input tube (1 $\mu \mathrm{g}$ genomic DNA) was adjusted to $200 \mu \mathrm{l}$ with IP buffer, respectively. (IP Buffer: 0.5\% NP40, 1.1\% Triton X-100, 1.5mM EDTA, $50 \mathrm{mM}$ Tris- $\mathrm{HCl}, 150 \mathrm{mM} \mathrm{NaCl}$ ). Anti-5-methyl cytidine antibody (5 $\mu \mathrm{g}$ ) (Diagenode, Liege, Belgium) and mouse lgG (5 $\mu \mathrm{g})$ (Jackson ImmunoResearch Laboratories, Inc., West Grove, PA, USA) were respectively added to the MeDIP tube and negative control tube followed by incubation at $94^{\circ} \mathrm{C}$ for 10 minutes. Nothing was added to the input tube. The three tubes were placed on a rotating wheel at $4^{\circ} \mathrm{C}$ for 4 hours, after which $50 \mu$ l of BiomagTM magnetic beads (Bangs laboratories, Inc., Fishers, IN, USA) were added. After capturing the beads using a magnet, the supernatant was transfered to a new tube, and a mix of phenol/chloroform/isoamylalcohol (25:24:1, 200 $\mathrm{\mu l})$ was added to the MeDIP, negative control and input tube. After centrifugation, the aqueous phase was transferred into a new $1.5 \mathrm{ml}$ tube, and then $\mathrm{NaCl}$ (final concentration of $200 \mathrm{mM})$, glycogen $(3 \mu \mathrm{g})$ and ethyl alcohol $(1000 \mu \mathrm{l})$ were added to the tubes. Tubes were placed at $-80^{\circ} \mathrm{C}$ for 30 minutes to precipitate the DNA, centrifuged at $13000 \mathrm{~g}$ for 20 minutes at $4^{\circ} \mathrm{C}$ to pellet DNA samples, and washed with $500 \mu \mathrm{l}$ of $70 \%$ ethyl alcohol. Each sample was re-suspended in $20 \mu \mathrm{l}$ of $10 \mathrm{mM}$ Tris- $\mathrm{HCl} / \mathrm{pH} 8.0$ after drying for $10 \mathrm{~min}$ at room temperature.

Forty microliter of the Cy3 and Cy5 dye-labeled random primer (TriLink Biotechnologies, San Diego, CA, USA) were respectively added to the MeDIP and input sample. Twenty microliter of dNTP/Klenow master mix (NEB, Ipswich, MA, USA) was added to each of sample after heat-denaturing at $98^{\circ} \mathrm{C}$ for 10 minutes. Each sample was incubated for 2 hours at $37^{\circ} \mathrm{C}$, then the pellets were rehydrated in $25 \mu \mathrm{l}$ water under vortexing and centrifugation. Components of the Hybridization Kit 40 (Roche NimbleGen, Madison, WI, USA) were added to each sample for hybridization. This procedure was conducted in the Hybridization System (Roche NimbleGen) using NimbleChip X1 Mixer (Roche NimbleGen) according to the manufacturer's instruction. Finally, microarray

Table 1. MSP primer and reaction conditions.

\begin{tabular}{|c|c|c|c|c|}
\hline Gene and Primer Set* & Forward primer $5^{\prime}$ to $3^{\prime}$ & Reverse primer $5^{\prime}$ to $\mathbf{3}^{\prime}$ & $\begin{array}{l}\text { Size } \\
\text { (bp) }\end{array}$ & $\begin{array}{c}\text { Annealing temperature }{ }^{\circ} \mathrm{C} \\
\text { / cycles }\end{array}$ \\
\hline COL18A1 M & CGTAGGTGTTTTTTGGTTATGGTC & GAATCTTACCTAACTCCGCGAA & 109 & $58.5 / 35$ \\
\hline COL18A1 U & GTGTAGGTGTTTTTTGGTTATGGTT & СССАААТСТТАССТААСТССАСА & 113 & $58 / 35$ \\
\hline EP300 M & TCGAGAATGTGGTGGAATC & AAAAAATAAAAACGCACCGA & 159 & $59 / 36$ \\
\hline EP300 U & TGGTTGAGAATGTGGTGGAATT & TAAAAAAATAAAAACACACCAAA & 159 & $55 / 36$ \\
\hline GNAS M & CGGTCGAGGTAATAAGAGC & CCGAAACCGAAAAAACTAAT & 109 & $58 / 35$ \\
\hline GNAS U & GTTTGGTTGAGGTAATAAGAGT & AAACCAAAACCAAAAAAACTAAT & 109 & $55 / 35$ \\
\hline SMURF1 M & GGTTAGAGCGTCGTAGTAAGC & TTACGACTCCGAACTAAACG & 119 & $58.5 / 35$ \\
\hline SMURF1 U & GAGGGTTAGAGTGTTGTAGTAAGT & TTACAACTCCAAACTAAACACCA & 119 & $55.5 / 35$ \\
\hline
\end{tabular}

* $M$, methylated sequence; $U$, unmethylated sequence. 
scanning was performed in the GenePix 4000B (Molecular Devices, Inc., Sunnyvale, CA, USA). When the scan was completed, images taken at $532 \mathrm{~nm}$ and $635 \mathrm{~nm}$ wavelengths were saved. Data extraction was performed using GenePix Pro6.0 (Molecular Devices, Inc.).

\section{Methylation-specific polymerase chain reaction (MSP)}

The four top changed genes from the DNA methylation microarray, were validated for promoter methylation by MSP. Genomic DNA was extracted from frozen tissues following the Wizard Genomic DNA Purification Kit A1120 (Promega, Madison, WI, USA) protocol. Purified DNA was subjected to bisulfite modification using EZ DNA Methylation-Gold ${ }^{\mathrm{TM}}$ Kit D5005 (Zymo Research, Irvine, CA, USA) according to the manufacture's instruction. Primers for MSP, as shown in Table 1, were designed by using MethPrimer (http://www.urogene.org/methprimer/index1.html) (7) and Methyl Primer Express ${ }^{\circledR}$ Software v1.0. The PCR mixture contained $6.25 \mu \mathrm{l}$ of $2 x$ ZymoTaq premix polymerase (Zymo Research), $0.5 \mu$ l of forward primer $(10 \mu \mathrm{M}), 0.5 \mu$ l of reverse primer $(10 \mu \mathrm{M})$, and $0.5 \mu$ l of bisulfite treated DNA template in a final volume of $12.5 \mu \mathrm{l}$. Reactions were initially denatured at $95^{\circ} \mathrm{C}$ for 10 minutes followed by 35 or 36 cycles $\left(30 \mathrm{sec}\right.$ at $95^{\circ} \mathrm{C}$, $35 \mathrm{sec}$ at the annealing temperature listed in Table 1, and 45 sec at $72^{\circ} \mathrm{C}$ ), and finally followed by a 7 -min extension at $72^{\circ} \mathrm{C}$. Positive control was performed for each PCR set using Bisulfite Converted Universal Methylated Human DNA Standard (Zymo Reasearch). PCR products were separated by electrophoresis on $1.5 \%$ agrose gel, stained with ethidium bromide, and visualized under UV illumination. Results were confirmed by repeated tests to avoid any technical bias.

\section{Sequencing of MSP Products}

According to the results of MSP, samples which had a positive methylated signal at the promoter regions were sequenced directly. The MSP products were cloned into pCR2.1-Topo vector (Invitrogen, Waltham, MA, USA) and randomly picked clones were sequenced using the ABI-3730 PRISM sequencing kit (Applied Biosystems, Carlsbad, CA, USA) according to the manufacturer's protocol. The sequencing results were analysed using Chromas 2 (Technelysium Pty Ltd, South Brisbane, QLD, Australia).

\section{Real time polymerase chain reaction (real time PCR)} Total RNA was isolated following the TRIzol reagent (Invitrogen) protocol. Samples of $10 \mu \mathrm{g}$ of total RNA were separated by electrophoresis through a $1 \%$ agarose gel to check the quality. The quantity and purity of total RNA were detected by Biophotometer (Eppendorf, Hamburg, Germany). Real time PCR was performed and analysed with the iCycler iQTM multicolor Real-Time detection System (Bio-Rad, Tokyo, Japan). Primers were designed using Primer Premier 5.0 and are shown in Table 2. For each sample, $1 \mu \mathrm{g}$ of total RNA was subjected to reverse transcription using the PrimeScriptTMRT reagent kit (Takara, Otsu, Japan) according to the manufacturer's instructions. The PCR mixture contained $12.5 \mu$ l of 2x SYBR Green Buffer, $1 \mu$ of forward primer $(10 \mu \mathrm{M}), 1 \mu \mathrm{l}$ of reverse primer $(10 \mu \mathrm{M})$, and 2 $\mu \mathrm{l}$ of reverse-transcribed products in a final volume of $25 \mu \mathrm{l}$. Reactions were initially denatured at $95^{\circ} \mathrm{C}$ for $10 \mathrm{sec}$ followed by 40 cycles of denaturation at $95^{\circ} \mathrm{C}$ for $5 \mathrm{sec}$, annealing and extension at $60^{\circ} \mathrm{C}$ for $45 \mathrm{sec}$. Fluorescence data were acquired at $60^{\circ} \mathrm{C}$ during each cycle. To determine the specificity of the PCR reactions, melt curve analysis was carried out after amplification by slow heating from 55 to $95^{\circ} \mathrm{C}$, with fluorescence acquisition at $1^{\circ} \mathrm{C}$ intervals and a $5 \mathrm{sec}$ hold at each increment. The expression of $\beta$-actin was used for normalization of transcription and a "no template" sample was used as a negative control. The relative expression unit was determined using the Gene Expression Macro Version 1.1 software (Bio-Rad Laboratories Inc.). Samples were analysed in triplicates.

\section{Immunohistochemistry (IHC)}

Four micrometer sections were obtained from paraffin embedded specimens and stained using the avidin-biotin complex method. COL18A1 codes the a chain of type XVIII collagen, and the C-terminal of type XVIII collagen formed Endostatin. Immunochemical staining was carried out using the Endostatin antibody [1837-46](Abcam Inc, Cambridge, MA, USA), which is a mouse monoclonal antibody against the recombinant fragment

Table 2. Real-time PCR primer and reaction conditions.

\begin{tabular}{|c|c|c|c|c|}
\hline Gene & Forward primer $5^{\prime}$ to $3^{\prime}$ & Reverse primer $5^{\prime}$ to $3^{\prime}$ & $\begin{array}{l}\text { Size } \\
\text { (bp) }\end{array}$ & $\begin{array}{c}\text { Annealing temperature }{ }^{\circ} \mathrm{C} \\
\text { / cycles }\end{array}$ \\
\hline COL18A1 & CTGACCGAGAGCTACTGTGAGAC & GCAGAGCACGATGTAGGCG & 140 & $60 / 40$ \\
\hline EP300 & GAGACACGCTGGCACTGTACT & GCTCTCATCATCTAAGCCAAGG & 117 & $60 / 40$ \\
\hline GNAS & GAGTGGACTACATCCTGAGTGTG & GTACTCGTTGGAGCGTTCGTAG & 128 & $60 / 40$ \\
\hline SMURF1 & GAACCAGCCCCTTACACAGATAG & CGTCTGTAGTGAACCTCGCAC & 139 & $60 / 40$ \\
\hline$\beta$-actin * & CTCCATCCTGGCCTCGCTGT & GCTGTCACCTTCACCGTTCC & 268 & $60 / 40$ \\
\hline
\end{tabular}

* $\beta$-actin was used for normalization of transcription. 


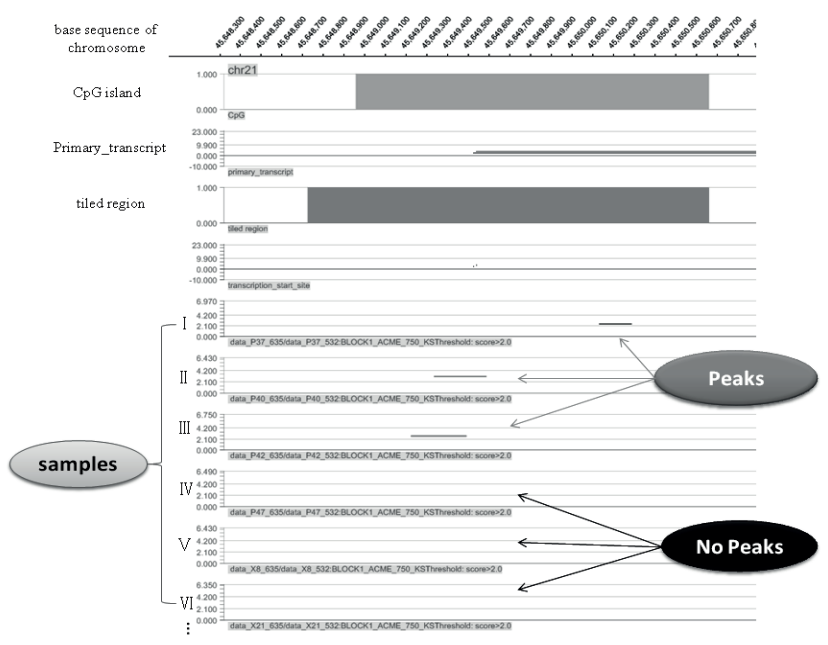

Figure 1. Interpretation of screening changed genes by observing the presence or absence of peaks. Note: Peaks- methylated signal in a particular genetic locus.

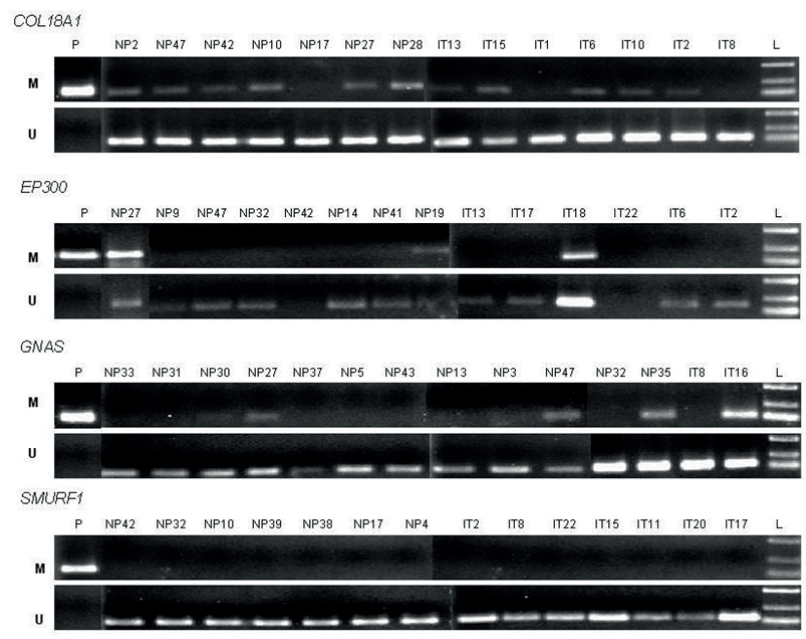

Figure 2. Representative MSP results for COL18A1, EP300, GNAS and SMURF1. Note: P-positive control; NP- nasal polyps; IT- inferior turbinate; $\mathrm{M}$ - methylated signal; $\mathrm{U}$ - unmethylated signal; L- size marker. Interpretation of figure: $\mathrm{M}(+)$ and $\mathrm{U}(-)$ : methylation; $\mathrm{M}(+)$ and $\mathrm{U}(+)$ : incomplete methylation; $\mathrm{M}(-)$ and $\mathrm{U}(+)$ : unmethylation. of the C-terminus of type XVIII collagen. In brief, the sections were dewaxed in xylene and dehydrated in alcohol (100\%, 95\% and $80 \%$ for 2 minutes, respectively). The antigen was repaired by Tris-EDTA ( $\mathrm{pH} 9.0)$ using a microwave oven $\left(80^{\circ} \mathrm{C}, 10 \mathrm{~min}\right.$ and $\left.60^{\circ} \mathrm{C}, 6 \mathrm{~min}\right)$. Then, sections were blocked by $3 \%$ hydrogen peroxide. Endostatin antibody was added to each section with $50 \mu \mathrm{l}$ goat serum and incubated overnight at $4^{\circ} \mathrm{C}$. A secondary antibody coated with peroxidase labeled polymer was subsequently added to each section and incubated for $30 \mathrm{~min}$ at $37^{\circ} \mathrm{C}$. Then, DAB substrate chromogen was added to each slide for color development. In the end, sections were counterstained with hematoxylin, dehydrated with a ethanol series (80\%, 90\%, 100\%, and $100 \%$ for 2 minutes, respectively). After that, the slides were toasted at $37^{\circ} \mathrm{C}$ and fixed with a coverslip. Control for nonspecific staining was routinely performed with PBS instead of primary antibodies with the other procedures identical as for the specific staining. The slides were observed in a blinded fashion by the same pathologist using a cell counting technique ${ }^{(8)}$, which calculated positively stained cells at $400 x$ magnification in ten randomly selected fields.

\section{Statistical analysis}

Statistical analysis was performed with SPSS 12.0 for Windows (SPSS Inc., Chicago, IL, USA). Based on the distribution of data, which was assessed by the one-sample Kolmogorov-Smirnov test, the Mann-Whitney $U$ test was adopted for comparison of real-time PCR data between the NP and IT groups. The chi-square test was used to compare MSP results. The Wilcoxon signedrank test was applied to evaluate IHC results. All tests were two tailed, and the level of significance was set at $p<0.05$.

Table 3. Screening details of four top changed gene of DNA Methylation Microarray.

\begin{tabular}{|c|c|c|c|c|c|c|c|c|c|}
\hline $\begin{array}{l}\text { Gene } \\
\text { name }\end{array}$ & Accession & $\begin{array}{l}\text { Chromo- } \\
\text { some }\end{array}$ & Strand & $\begin{array}{l}\text { Trans } \\
\text { start }\end{array}$ & Trans end & $\begin{array}{l}\text { Locus } \\
\text { link ID }\end{array}$ & Protein ID & Protein name & $\begin{array}{l}\text { CpG island loca- } \\
\text { tion }\end{array}$ \\
\hline COL18A1 & NM_130445 & chr21 & + & 45649524 & 45758062 & 80781 & NP_569712 & $\begin{array}{c}\text { alpha } 1 \text { type XVIII } \\
\text { collagen isoform } 2 \\
\text { precursor }\end{array}$ & $\begin{array}{c}\text { chr21:45648959- } \\
45650662\end{array}$ \\
\hline GNAS & NR_003259 & chr20 & + & 56897574 & 56919642 & 2778 & NP_001070957 & $\begin{array}{l}\text { GNAS complex locus } \\
\text { isoform g }\end{array}$ & $\begin{array}{c}\text { chr20:56897047- } \\
56901134\end{array}$ \\
\hline EP300 & NM_001429 & chr22 & + & 39818559 & 39906027 & 2033 & NP_001420 & $\begin{array}{l}\text { E1A binding protein } \\
\text { p300 }\end{array}$ & $\begin{array}{c}\text { chr22:39817207- } \\
\text { 39819105 }\end{array}$ \\
\hline SMURF1 & NM_020429 & chr7 & - & 98579659 & 98462999 & 57154 & NP_065162 & $\begin{array}{c}\text { Smad ubiquitination } \\
\text { regulatory factor } 1 \\
\text { isoform }\end{array}$ & $\begin{array}{c}\text { chr7:98579141- } \\
98579926\end{array}$ \\
\hline
\end{tabular}




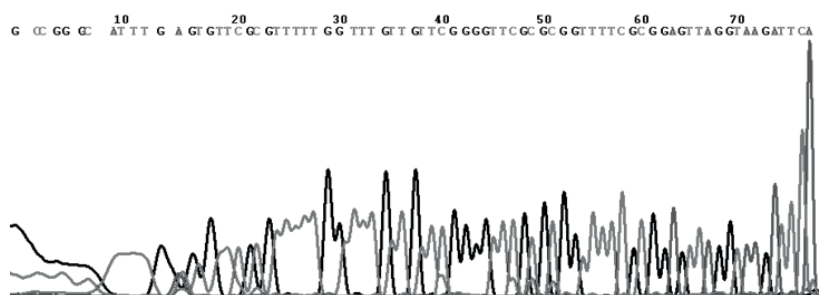

(a)

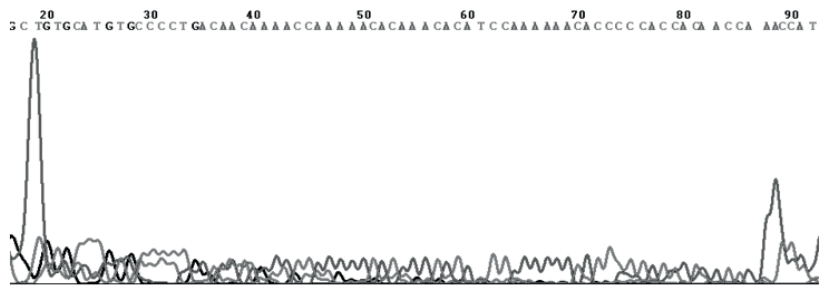

(b)

Figure 3. Results of sequencing MSP products of COL18A1. (a) methylated signal sample of MSP. (b) unmethylated signal sample of MSP.
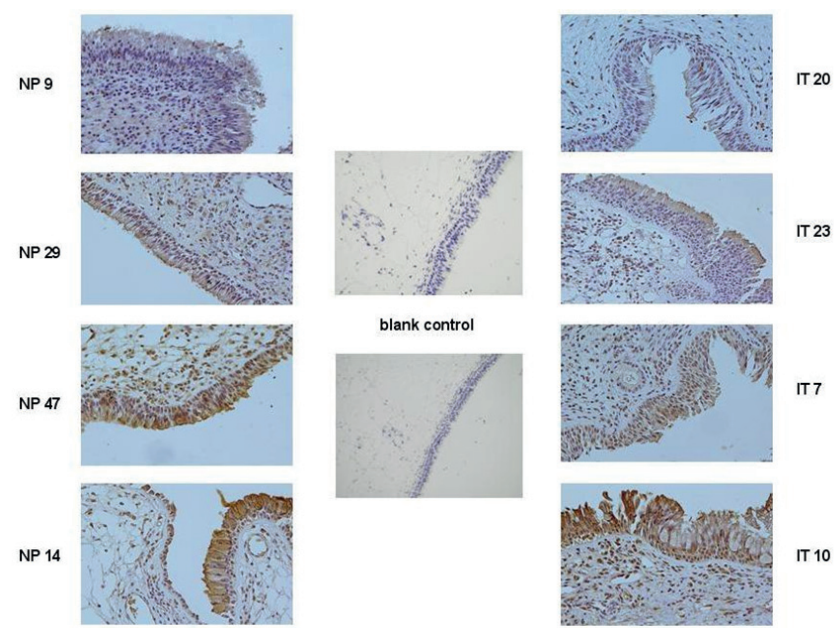

Figure 4. Immunohistochemical staining and blank control samples of COL18A1. Note: NP-nasal polyps; IT-inferior turbinate; blank control-not apply any primary antibody.

\section{Results}

Detection of DNA methylation by microarray

Raw data were extracted as pair files by NimbleScan software. Then, a series of procedures were performed to get the Peaks data with specified parameters (sliding window width: 750bp; mini probes per peak: 2; P-value minimum cutoff: 2; maximum spacing between nearby probes within peak: $500 \mathrm{bp}$ ). If a sample had a Peaks value in a particular genetic locus, it showed that this region had a hypermethylated signal. After obtaining the Peaks data, we mapped it with genomic features: transcripts and CpG islands. NimbleGen's SignalMap ${ }^{\text {TM }}$ data browser (Roche NimbleGen, USA) was used to visually interpret the Peaks data as shown in Figure 1. The summary of the data for all samples were imported into a Microsoft Excel document for analysis. DNA methylation microarray analysis identified 8,008 CpG islands in 2,848 genes. One hundred and ninety-eight genes were found to have a methylated signal in their promoter region

Table 4. Comparison of methylation frequency of COL18A1 between NP and ITM samples.

\begin{tabular}{cccc} 
Group & $\begin{array}{c}\text { Cases of } \\
\text { methylation }\end{array}$ & $\begin{array}{c}\text { Cases of un- } \\
\text { methylation }\end{array}$ & $\begin{array}{c}\text { Percentage of } \\
\text { methylation } \\
(\%)\end{array}$ \\
\hline NP & 27 & 5 & 84.38 \\
ITM & 9 & 9 & 50.00 \\
\hline
\end{tabular}

$\chi 2=6.75, \mathrm{p}<0.01 *$ by Chi-Square test; NP, nasal polyp; ITM, inferior turbinate mucosa. when comparing NP samples with ITM samples. The four most changed genes, COL18A1, EP300, GNAS and SMURF1, were selected for further study (Table 3).

\section{Validation of promoter methylation by MSP}

Among the total samples analysed by MSP, a strongly methylated signal appeared in the promoter region of COL18A1 (27 NP samples and 9 ITM samples, respectively). Only three and five samples showed a methylated signal in the promoter region of EP300 and GNAS, respectively. No methylated signal was detected in any sample in the promoter region of SMURF1. However, an unmethylated signal existed in the promoter region of COL18A1, EP300, GNAS and SMURF1 in all samples. Representative MSP results for these genes are presented in Figure 2. Table 4 shows that the methylation frequency of COL18A1 was significantly higher in NP samples than in ITM samples. The results of MSP for EP300, GNAS and SMURF1 showed no

Table 5. Comparison of mRNA level between NP and ITM samples (mean $\pm \mathrm{SD})$

$\begin{array}{ccccc}\text { Gene } & & & & \\ & \text { COL18A1 } & \text { EP300 } & \text { GNAS } & \text { SMURF1 } \\ \text { NP } & 15.53 & 272.30 & 13382.33 & 29.64 \\ & \pm 24.62 & \pm 116.57 & \pm 16173.53 & \pm 26.47 \\ \text { ITM } & 9.14 & 292.64 & 22594.00 & 31.73 \\ & \pm 6.84 & \pm 88.47 & \pm 18891.72 & \pm 26.18 \\ & * Z=-0.747 & +F=0.409 & +F=11.583 & * Z=-0.736 \\ & p=0.455 & p=0.525 & p=0.001 & p=0.462 \\ & & & & \\ \end{array}$

* by Mann-Whitney U test (non-normal distribution); † by One-Way ANOVA (normal distribution). NP, nasal polyp; ITM, inferior turbinate mucosa. 


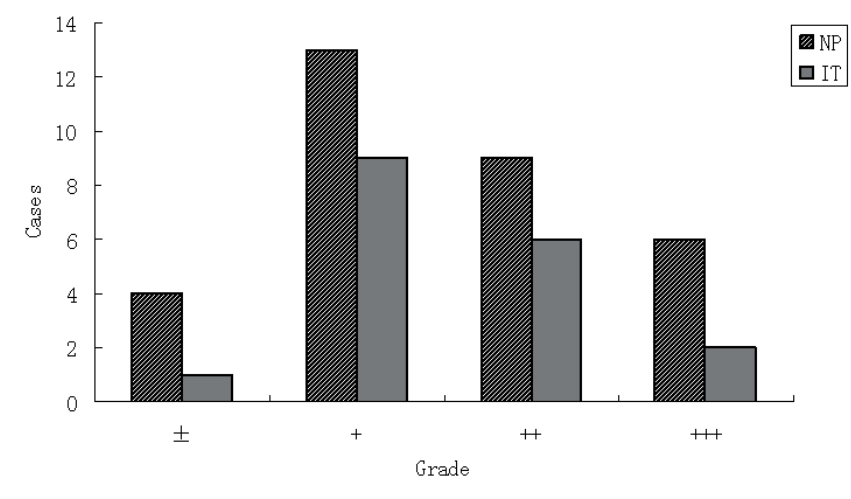

Figure 5. Level of COL18A1 protein between NP and ITM samples as assessed by cell counting. Note: NP-nasal polyps; IT-inferior turbinate; weak positive $( \pm)$; positive $(+)$; moderate positive $(++)$; severe positive $(+++)$. Statistical result: $\mathrm{u}=0.085, \mathrm{p}>0.05$ (Wilcoxon signed-rank test).

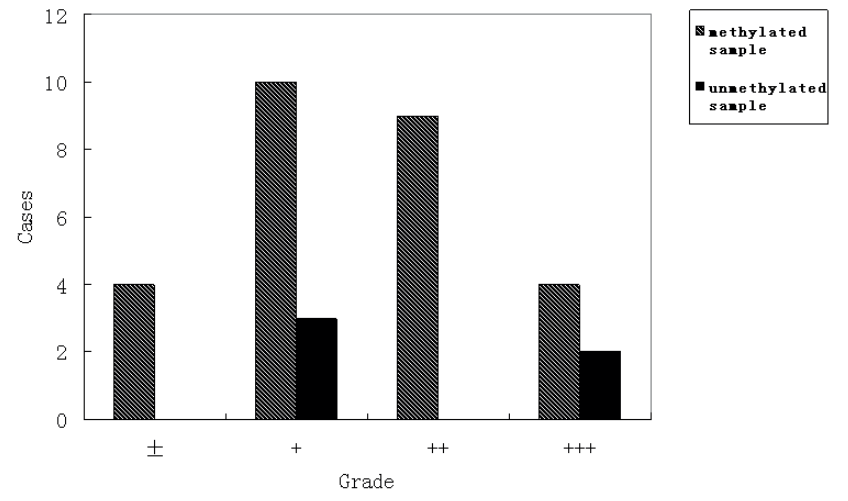

Figure 6. Level of COL18A1 protein between the methylated and unmethylated NP samples as assessed by cell counting. Note: NP-nasal polyps; weak positive $( \pm)$; positive $(+)$; moderate positive $(++)$; severe positive $(+++)$. Statistical result: $u=0.491, p>0.05$ (Wilcoxon signedrank test). significant difference in methylation frequency between NP and ITM samples.

\section{Results of sequencing MSP products of COL18A1}

For validation of the detailed methylation status of the promoter region of COL18A1, sequencing analysis was performed as shown in Figure 3. Results demonstrated that most of the cytosines at cytosine-phosphate-guanine $(\mathrm{CpG})$ sites were unchanged, and the cytosines at non-CpG sites of the original sequence were converted to thymines after bisulphite modification, verifying that these $\mathrm{CpG}$ sites were methylated.

\section{Confirmation of gene expression by real time PCR}

The expression of mRNA for these genes (COL18A1, EP300, GNAS and SMURF1) was confirmed by real-time PCR as shown in Table 5. There was no significant difference between NP and ITM samples in the level of mRNA for COL18A1, despite the difference between the two groups in the methylation frequency of COL18A1. In contrast, GNAS showed the opposit: no difference in methylation frequency, but a significant difference in mRNA levels. The mRNA levels of EP300 and SMURF1 did not differ significantly between NP and ITM samples, consistent with the results of MSP.

\section{IHC for COL18A1}

Based on the results of MSP and sequencing analysis, IHC was used to evaluate the expression of COL18A1 protein. Staining was observed in all NP and ITM tissues, mainly in the cytoplasm and extracellularly (Figure 4). The level of COL18A1 protein did not differ significantly between NP and ITM samples as assessed by cell counting (Figure 5 ). Further analysis showed that COL18A1 protein expression did not differ significantly between the methylated and unmethylated NP samples (Figure 6).

\section{Discussion}

In recent years, studies on the interaction of environmental factors and genes that lead to disease have become increasingly popular. The function of epigenetic regulation of gene expression provides a new perspective on the pathogenesis of allergic diseases ${ }^{(9)}$. DNA methylation, one of the research foci in epigenetics, has recently been shown to have an important link with allergic disease and atopy. Janson et al. ${ }^{(10)}$ showed that methylation of the FOXP3 promoter could regulate the activity of Treg cells and that Treg cells had important roles in self-tolerance. Kwon et al. ${ }^{(11)}$ found that in patients with asthma, the methylation status of CpG sites of the IFNG gene were important in regulating the expression of inflammatory cytokines. During early childhood, an excessive exposure to microbes could induce demethylation of IFNG in naive T cells, which increases the risk of allergic diseases ${ }^{(12)}$.

DNA microarray has recently been applied to study gene expression in the pathogenesis of NP. With the use of gene chips and related techniques, researchers have found differences between NP and the normal nasal mucosa in expression of genes, providing a new direction for research into NP ${ }^{(13-17)}$. However, none of these studies investigated DNA methylation. In this study, we used a DNA methylation microarray, which is a combination of immunoprecipitation of methylated DNA and DNA microarray ${ }^{(6)}$, to detect the methylation status of CpG islands in NP. Inferior turbinate mucosa has been used as control tissue in some previous studies ${ }^{(15,17)}$. Polypoid changes may have occurred in the ITM tissues of CRS patients, especially in those with NPs. For this reason, the result will be biased if NP and ITM tissues from the same CRS patient was used for methylation comparison. Therefore, patients free of any nasal or sinus disease were recruited as a control group to accurately detect differen- 
ces between NP tissue and normal nasal mucosa.

COL18A1 encodes the Type XVIII collagen $\alpha$ chain, the cleaved C-terminal fragment that constitutes endostatin, which can inhibit endothelial cell proliferation and angiogenesis. Endostatin has been reported to prevent endothelial cell migration and adhesion and induce endothelial cell apoptosis, inhibit tumour formation and growth, prevent the proliferation of cancer cells and reduce tumour recurrence rates ${ }^{(18-22)}$. Functional changes in COL18A 1 could influence the production of endostatin, resulting in a lack of inhibition of endothelial cells and possible tumour development. Expression of COL18A1 in plasma and tissue was useful as a prognostic marker in gastric cancer, non-small cell lung cancer, thyroid and pancreatic cancer ${ }^{(23-27)}$. Moreover, Castro et al. ${ }^{(28)}$ reported that COL18A1 was associated with atopy by genome-wide analysis of atopy patients with and without asthma. Suzaki et al. ${ }^{(29)}$ found that endostatin could prevent the development of asthma in a mouse model. Therefore, COL18A1 might play an important role in the formation and development of allergic diseases.

In the present study, we found that the methylation level of the COL18A1 promoter region differed significantly between the ITM and NP groups, a result that was verified by MSP and bisulphite sequencing. However, when the levels of mRNA and protein expression of COL18A1 were evaluated, it was found that there were no significant differences between the ITM and NP samples. We propose the following possible reason for this phenomenon. COL18A1 has two or more promoters and several splice variants, but in the microarray just one promoter was found to have a hypermethylated signal, which was at genomic sequence of NC_000021.8 Chr21 Reference GRCh37.p13 Primary Assembly. It is supposed that the single promoter methylation did not inhibit mRNA transcription and protein expression. This can be a reason why no differences were present in the results of real-time PCR and IHC experiments. Moreover, a wide range of factors, including epigenetic changes, gene rearrangement, changes in chromatin structure, cis-acting elements, transacting factors, microRNA and post-translational regulation can regulate the process of DNA transcription to mRNA and its subsequent translation into protein. DNA methylation has been regarded as a key regulator of gene activity, but there are still many unknowns remained to be answered.

The main focus of our study was to perform a pilot screening and verification whether genes were differentially methylated in NP. Therefore, further studies, like using primers specifically targeting splice variants, are needed to explore the role of DNA methylation in the pathogenesis of NP. In addition, only seven of 32 NP patients in this study had positive results in the allergen skin prick test, a much lower proportion than has been found in European studies ${ }^{(30-32)}$. This might imply that the pathogenesis of NP differs between different racial groups.

\section{Conclusions}

From the present study, we deduced that DNA methylation may play an important role in the pathogenesis of NP. Promoter methylation of COL18A1 was found to be significantly increased in NP tissues. Further studies are necessary to confirm the significance of these epigenetic factors in the mechanisms underlying the development or persistence of nasal polyps.

\section{Acknowledgements}

This study was supported by the National Natural Science Foundation of China (No. 30801280). Analysis of DNA methylation microarray was commercially assisted by KangChen Bio-tech Co., Ltd., Shanghai, China.

\section{Author contributions}

YBZ: contributed to specimen collection, experimental design, experimental operation, data acquisition, result analysis and manuscript writing. YZ: contributed to experimental design, process supervision, result analysis and manuscript writing. LYY: contributed to experimental operation, data acquisition and manuscript writing. PL: contributed to experimental design and result analysis. YFL, JMX, GYZ: contributed to specimen collection and data acquisition. DYW: contributed to experimental design, process supervision and result analysis.

\section{Conflict of interest}

We declare no conflict of interest in this study.

\section{References}

1. Fokkens WJ, Lund VJ, Mullol J, on behalf of the European Position Paper on Rhinosinusitis and Nasal Polyps group. European position paper on rhinosinusitis and nasal polyps 2012. Rhinol Suppl. 2012 (23): 1-298.

2. Bateman ND, Fahy C, Woolford TJ Nasal polyps: still more questions than answers. Laryngol Otol. 2003; 117: 1-9.

3. Alexiou A, Sourtzi P, Dimakopoulou K Manolis E, Velonakis E. Nasal polyps: hered- ity, allergies, and environmental and occupational exposure. J Otolaryngol Head Neck Surg. 2011; 40: 58-63.

4. White GP, Hollams EM, Yerkovich ST, et al. CpG methylation patterns in the IFNgamma promoter in naive T cells: variations during Th1 and Th2 differentiation and between atopics and non-atopics. Pediatr Allergy Immunol. 2006; 17: 557-564.

5. Baron U, Floess S, Wieczorek G, et al. DNA demethylation in the human FOXP3 locus discriminates regulatory $T$ cells from acti- vated FOXP3(+) conventional T cells. Eur J Immunol. 2007; 37: 2378-2389.

6. Weber M, Davies JJ, Wittig D, et al. Chromosome-wide and promoter-specific analyses indentify sites of differential DNA methylation in normal and transformed human cells. Nat Genet. 2005; 37: 853-862.

7. Li LC, Dahiya R. MethPrimer: designing primers for methylation PCRs. Bioinformatics. 2002; 18: 1427-1431.

8. Yu P, Bu H, Wang H, Zhao G, Zhang J, Zhou Q. Comparative study on image analysis 
and manual counting of immunohistochemistry. Sheng Wu Yi Xue Gong Cheng Xue Za Zhi. 2003; 20: 288-290.

9. Isidoro-García M, Dávila-González I, Pascual de Pedro M, Sanz-Lozano C, LorenteToledano F. Interactions between genes and the environment. Epigenetics in allergy. Allergol Immunopathol (Madr). 2007; 35: 254-258.

10. Janson PC, Winerdal ME, Marits $P$, Thörn $M$ Ohlsson R, Winqvist O. FOXP3 promoter demethylation reveals the committed Treg population in humans. PLoS One. 2008; 20; 3: e1612.

11. Kwon NH, Kim JS, Lee JY, Oh MJ, Choi DC. DNA methylation and the expression of IL-4 and IFN-gamma promoter genes in patients with bronchial asthma. J Clin Immunol. 2008; 28: 139-146.

12. Vuillermin PJ, Ponsonby AL, Saffery $R$, et al. Microbial exposure, interferon gamma gene demethylation in naïve T-cells, and the risk of allergic disease. Allergy 2009; 64(3):348-53.

13. 13. Fritz SB, Terrell JE, Conner ER, Kukowska-Latallo JF, Baker JR. Nasal mucosal gene expression in patients with allergic rhinitis with and without nasal polyps. J Allergy Clin Immunol. 2003; 112: 1057-1063.

14. Liu Z, Kim J, Sypek JP, et al. Gene expression profiles in human nasal polyp tissues studied by means of DNA microarray. J Allergy Clin Immunol. 2004; 114: 783-790.

15. Lee JY, Lee SH, Lee HM, et al. Analysis of gene expression profiles of normal human nasal mucosa and nasal polyp tissues by SAGE. J Allergy Clin Immunol. 2006; 118: 134-142.

16. Stankovic KM, Goldsztein $H$, Reh DD, Platt MP, Metson R. Gene expression profiling of nasal polyps associated with chronic sinusitis and aspirin-sensitive asthma. Laryngoscope. 2008; 118: 881-889.

17. Wu J, Bing $L$, Jin $H$, Jingping F. Gene expression profiles of nasal polyps associated with allergic rhinitis. Am J Otolaryngol. 2009; 30:
24-32.

18. Heljasvaara R, Nyberg P, Luostarinen J, et al. Generation of biologically active endostatin fragments from human collagen XVIII by distinct matrix metalloproteases. Exp Cell Res. 2005; 307: 292-304.

19. Ergün S, Kilic N, Wurmbach $\mathrm{JH}$, et al. Endostatin inhibits angiogenesis by stabilization of newly formed endothelial tubes. Angiogenesis. 2001; 4: 193-206.

20. Zhang Y, Qu ZH, Cui M, et al. Combined endostatin and TRAIL gene transfer suppresses human hepatocellular carcinoma growth and angiogenesis in nude mice. Cancer Biol Ther. 2009; 8: 466-473.

21. Tilki D, Kilic N, Herbst $H$, et al. High level of endostatin in epididymal epithelium: protection against primary malignancies in this organ?. Histochem Cell Biol. 2008; 130: 527-535.

22. Yokoyama Y, Sedgewick G, Ramakrishnan S Endostatin binding to ovarian cancer cells inhibits peritoneal attachment and dissemination. Cancer Res. 2007; 67: 10813-10822.

23. Lurje $G$, Husain $H$, Power DG, et al. Genetic variations in angiogenesis pathway genes associated with clinical outcome in localized gastric adenocarcinoma. Ann Oncol. 2010; 21: 78-86

24. Woo IS, Kim KA, Jeon HM, et al. Pretreatment serum endostatin as a prognostic indicator in metastatic gastric carcinoma. Int J Cancer. 2006; 119: 2901-2906.

25. lizasa $T$, Chang $H$, Suzuki $M$, et al. Overexpression of collagen XVIII is associated with poor outcome and elevated levels of circulating serum endostatin in non-small cell lung cancer. Clin Cancer Res. 2004; 10: 5361-5366

26. Hoffmann S, Wunderlich A, Lingelbach S, et al. Expression and secretion of endostatin in thyroid cancer. Ann Surg Oncol. 2008; 15: 3601-3608

27. Ohlund D, Ardnor B, Oman M, Naredi P, Sund M. Expression pattern and circulating levels of endostatin in patients with pancreas cancer. Int J Cancer. 2008; 122:
2805-2810.

28. Castro-Giner F, Bustamante M, Ramon González J, et al. A pooling-based genomewide analysis identifies new potential candidate genes for atopy in the European Community Respiratory Health Survey (ECRHS). BMC Med Genet. 2009; 10: 128.

29. Suzaki Y, Hamada K, Sho M, et al. A potent antiangiogenic factor, endostatin prevents the development of asthma in a murine model. J Allergy Clin Immunol. 2005; 116: 1220-1227.

30. Zhang N, Holtappels G, Gevaert P, et al. Mucosal tissue polyclonal lgE is functional in response to allergen and SEB. Allergy. 2011; 66: 141-148.

31. Muñoz del Castillo F, Jurado-Ramos A Fernández-Conde $\mathrm{BL}$, et al. Allergenic profile of nasal polyposis. J Investig Allergol Clin Immunol. 2009; 19: 110-116.

32. Erbek SS, Erbek S, Topal O, Cakmak O. The role of allergy in the severity of nasal polyposis. Am J Rhinol. 2007; 21: 686-690.

Yu Zhao, MD, PhD.

Department of Otorhinolaryngology

Head \& Neck Surgery

West China Hospital

Sichuan University

No.37 Guo Xue Xiang

Wu Hou District

Chengdu, Sichuan

China, 0086-610041

Telephone: +86-189-80601410

Fax: +86-028-8558 2944

E-mail:yutzhao@163.com 